\title{
From Whole Number to Real Number: Applying Rasch Measurement to Investigate Threshold Concepts
}

\author{
Caroline Long \\ The Centre for Evaluation and Assessment, University of Pretoria \\ caroline.long@up.ac.za
}

\begin{abstract}
The developments in mathematics that take place in Grades 7 to 9 constitute critical nodes in a learner's schooling. One of the major transitions to be made is from whole numbers to real numbers, which involves the understanding of rational (and irrational) numbers, and concepts such as ratio, proportion and percent. I hypothesise that ratio is a threshold concept that provides the conceptual gateway to higher order concepts. The research problem is to describe the learning challenges and provide an array of insights and strategies that will inform teaching. The theory of conceptual fields provides the framework for this research (Vergnaud, 1988). The Rasch measurement model (Rasch, 1960/1980) articulates the qualitative and quantitative aspects of the research. This paper provides an overview of the broader study and reports on an aspect of the data analysis.
\end{abstract}

\section{From whole number to real number}

Usiskin (2005) highlighted the critical mathematical developments that take place during the "transition years", most notably the transition from whole number ${ }^{1}$ to real number. In a detailed mathematical analysis of the unfolding development of number systems from whole numbers to fractional numbers, fractional numbers to rational numbers, and rational numbers to real numbers, Skemp (1971) notes that there are both smooth assimilations and difficult accommodations that take place in this unfolding. Each new system retains elements of the previous system, but introduces new notation, new meanings to operations, and contributes additional rules.

In each new [number] system there are sub-sets which are isomorphic ${ }^{2}$ with earlier systems. This [isomorphism] allows us to move freely from one number system to another, and also to mix systems provided that each one is operated according to its own methods. The overall result is a conceptual system of enormous power and flexibility (Skemp, 1971, p. 226).

It is this structure of number systems, where aspects of the system, for example the fraction notation used for both fraction and ratio, deceptively alike and yet subtly different, that is the Rubicon for most learners of mathematics as they make the transitions from whole numbers to rational numbers and then to real numbers. The assimilation into existing schemas and accommodating existing schemas to incorporate new

\footnotetext{
${ }^{1}$ The term whole number is used by Usiskin (2005). In the sense it is used here the term whole number can be used interchangeably with natural number.

${ }^{2}$ Two number systems are isomorphic if 1 ) there is a mapping of one into the other that puts them into one-to-one correspondence. 2) under this mapping, sums and products are preserved.
} 
concepts is a challenge for most learners. This accommodation is particularly challenging in the topic of percent. As Parker and Leinhardt (1995) note, percent is a dense language, where the changing meanings are not always accommodated into existing schema. In the Chinese curriculum, the term percent ratio is used (Cai \& Sun, 2002). This term indicates the close relationship between percent use and ratio. There is also however, a part whole use of percent which is closer to fraction use (Parker \& Leinhardt, 1995).

Challenges of major proportion in this domain are not new to the mathematics community. One of the major challenges confronted by the mathematicians of antiquity ( 340 B.C.) was the discovery that not all numbers could be represented by an integer over (divided by) an integer, of the type $\frac{a}{b}$. This critical understanding confronting the mathematicians was that there is no magnitude however small that will divide into both the side of a square and its diagonal. Similarly, there is no magnitude that will divide an integral number of times into both the diameter and the circumference of a circle. The startling fact that numbers like $\sqrt{2}$ could not be written as a ratio of two whole numbers and the equally startling fact that two line segments exist for which there is no common measure caused great consternation in the Pythagorean community in as far back as 340 B.C. (Eves, 1990). The historical account of how Eudoxus resolved the crisis through formulating a definition of ratio, based on magnitudes that were independent of whether numbers were commensurable or incommensurable, is a telling account of how mathematics developed in response to a question that concerned the mathematical community (Eves, 1990, p. 150). The concept of an irrational number is a threshold concept ${ }^{3}$ that is difficult to learn, but once grasped provides the conceptual gateway to higher mathematics.

This critical mathematical node has caused and still causes a measure of consternation among teachers and learners of mathematics today. According to Eves, "the incommensurable case was relegated to an appendix [in some textbooks], to be covered at the teacher's discretion, and sometimes it was omitted entirely, as being beyond the rigor of the course" (1980, p. 57). The omission of this crisis, and its resolution, from the high school topic of rational (and irrational numbers) is a tragedy, or at least a flaw, in that it leaves a conceptual gap in the understanding of irrational numbers. Irrational numbers are often introduced as non-terminating, non-repeating decimals, whereas the missing link is that the ratio of two incommensurable magnitudes will result in neither recurring nor terminating decimals.

My initial fascination with the concept of incommensurability, and irrational numbers (Long, 2006a), was temporarily replaced by a need to understand why the concept of ratio, and the consequent conceptualisation of rational numbers, a necessary precursor to the understanding of irrational numbers, is difficult to learn. Essentially the need to explore the topics of ratio and the related topics of fraction, proportion, and percent, for the purposes of teaching and learning ratio, proportion and percent has directed this research study. A further goal, through careful scaffolding of these pivotal concepts, is to contribute to an understanding of rational number, a threshold concept on the path to real number.

\section{Are ratio, proportion and percent difficult concepts?}

Usiskin (2005) describes one of the conceptual difficulties in the move from whole number to real number as the complexity of rational and real number concepts. For example 'fraction' has three different meanings, namely fraction as a number representing a quotient, as a number indicating a position between 0 and 1 and as a number that is not an integer. There are also different notations, fraction, decimal and percent, for the same number (Smith, 2002). Percent has a part whole meaning in addition to a ratio meaning depending on the context (Parker \& Leinhardt, 1995). According to Parker and Leinhardt, teachers and learners use the different meanings embedded in each particular problem situation intuitively but the conceptual differences are not necessarily made explicit.

The complexity of the real number system and indeed much of school mathematics provides a challenge for researchers in that "a single concept does not refer to only one type of situation, and a single situation cannot be analysed with only one concept" (Vergnaud, 1988, p. 141). Another complexity is that "a

\footnotetext{
${ }^{3}$ The term "threshold concept" and its meaning is attributed to Meyer and Land (2005).
} 
single concept develops not in isolation but in relationship with other concepts, through several kinds of problems and with the help of several wordings and symbolisms" (Vergnaud, 1988, p.141). In order to encompass the complexity it is therefore important to study conceptual fields.

A conceptual field is defined as a set of situations, the mastering of which requires mastery of several concepts of different natures (Vergnaud, 1988, p.142). It is broad enough to accommodate the complexity of related concepts and processes that are required to solve a "bulk" of problem situations, but not too unwieldy that it cannot provide a manageable research domain. The multiplicative conceptual field ${ }^{4}$ is conceptualised as "all situations that can be analysed as simple and multiple proportion problems and for which one usually needs to multiply or divide. Several kinds of concepts are tied to those situations in addition to the thinking required to master [the problems]" (Vergnaud, 1988, p. 141). Concepts include multiplication and division, fraction, ratio, rate, rational number, linear and non-linear functions, vector spaces and dimensional analysis. The development of proficiency in this field begins in the early grades and continues through high school and further.

Vergnaud (1988) notes that the study of cognitive development can only meaningfully take place in problem contexts in that a concept is not a true concept unless it is operationalisable. The complexity of a problem depends "on the structure of the problem, on the context domain, on the numerical characteristics of the data, and on the presentation" (Vergnaud, 1988, p. 143). However, as noted by Vergnaud (1988) the impact of these factors depend on the cognitive level of the student.

Vergnaud, asserts that while the origins of mathematical concepts lie in practical problems the power of mathematics lies in the process of transforming these intuitive and implicit knowledge first used in the solving of problems or a class of problems, into explicit and generalisable knowledge that can be applied to more than one situation. The necessity is therefore to describing mathematical concepts and cognitive processes in the mathematical language which makes explicit hierarchical progression (1988).

\section{TIMSS 1999 and 2003 results}

A secondary analysis of the Trends in International Mathematics and Science Study (TIMSS) 1999 and 2003 results investigating only the items which fell into the domain ratio, proportion and percent, showed that in general South African Grade 8 learners do not have an operational understanding of this domain; they are not able to solve problems in which these concepts are embedded. This predicament is not unique to South Africa as learning the concepts in this domain has provided challenges to learners in many countries (Hart, 1981; Parker \& Leinhardt, 1995; Vamvakoussi \& Vosniadou, 2007).

The secondary analysis was extended to the contextual data provided by the TIMSS study concerning both the intended and the implemented curriculum. A comparison of the South African curriculum with the TIMSS framework indicated insufficient attention to content detail (Long, 2006b, Mullis et al., 2003). This omission may be explained by the South African policy context, where it is expected that textbooks interpret the curriculum and provide teachers with additional support, beyond what is stated in the curriculum documents. According to teacher reports concerning the implemented curriculum, the topics relating to ratio were in some cases only taught to the "more able" children (Long, 2006b; Mullis et al., 2003; Reddy, 2006).

It is well known that the South African education system has a large tail of inefficient and dysfunctional schooling (Taylor, 2007), making it difficult to formulate policy or strategies for intervention based on national aggregated data alone. Therefore, in order to investigate the challenges confronting mathematics teaching and learning, selected TIMSS items were administered to learners at two well functioning schools at Grades 7, 8 and 9 level, comprising a sample of 330 learners. Subsequently interviews were conducted with selected learners for the purposes of further investigating the cognitive development of learners at these grades (Long, 2008).

\footnotetext{
${ }^{4}$ The additive conceptual field includes the set of situations for which additive structures are required and sufficient. The algebraic conceptual field builds on the additive and multiplicative conceptual fields.
} 


\section{Assessment instrument for ratio, proportion and percent items}

The requirement for designing an assessment instrument is firstly to have a clear idea of the domain to be tested, and to define the construct of interest (Wright \& Stone, 1979). This requirement is satisfied, more or less, in class tests and the matriculation examination, because experienced teachers have implicit knowledge of the curriculum and the kinds of questions that should be asked. In the case of this study the construct of interest is explicitly constructed as the multiplicative conceptual field, comprising the elements, fractions, ratio, proportion and percent.

A second requirement for any instrument is to contain items which will elicit reliable information about the domain to be tested. This precondition necessitated developing an instrument ${ }^{5}$ comprising items that are realisations of the construct and that would accurately target the population to be tested in terms of difficulty level. This requirement was assisted by having data available on the items from the TIMSS 2003 study so that the difficulty level of items for the South African Grade 8 population could be established (Long, 2008).

The third and fourth requirements, according to Wright and Stone (1979), are to demonstrate that the items when taken by a suitable population are consistent with expectations and that the patterns of learner responses are consistent with expectations. Finding unexpected responses in either the items or the learners requires an investigation of the items used to measure the construct and an investigation of the learner profile (including curricula and instructional experiences) on the test as a whole and consequently, if required, a deeper investigation of the construct being measured. In summary, any test functions as a test of the learner, a test of the test and the test designer, and in addition is a test of the defined construct being tested.

In all, 36 items $^{6}$ from the TIMSS released items were identified as located in the multiplicative conceptual field; these items constituted the research instrument. Some of the items had been categorised as belonging to the domain ratio, proportion and percent; however other items also exhibiting multiplicative structures had been categorised as geometry, measurement, data handling (probability), and algebra (patterns). As a proxy for a pilot test, the difficulty levels of the items were checked against the TIMSS 2003 South African results. In order to include some items that could provide information at the lower levels of proficiency, it was decided to include six Grade $4^{7}$ items.

\section{The Rash measurement model}

The prior empirical requirement of the Rasch model (Rasch, 1960/1980), concurring with Wright and Stone (1979), is to have an explicit understanding of the latent trait, that is, in the case of this research study proficiency in solving problems requiring the concepts fractions, ratio, proportion and percent, and to construct and refine an instrument made up of items that operationalise this trait. A feature of the Rasch model permits the discovery and amplification of item anomalies, which are inconsistent with the general expectations of the instrument. The test instrument used in this study proved to fit the requirement of the Rasch model of having a clearly defined domain.

The researcher is required to further investigate (post-hoc) any particular item shown to be misfitting, and if necessary eliminate the item, while at the same time identify a plausible explanation of the item misfit in terms of its own characteristics. One item, on the topic of probability did not discriminate between learners of greater proficiency and learners of less proficiency, as measured on the test as a whole. On further investigation it was inferred that probability had not been adequately taught and therefore this item was equally likely to be guessed by both high and low proficiency groups of learners, or to elicit an intuitive response, by both groups of learners.

\footnotetext{
${ }^{5}$ The development of an instrument implies the development of a measure that makes the outcome meaningful.

${ }^{6}$ One item was rejected making only 35 items.

${ }^{7}$ TIMSS 2003 conducted mathematics testing at Grades 8 and 4 only
} 
Likewise data from learners who for some or other reason do not perform as expected can be eliminated from the analysis, on the basis of explicit reasoned arguments, for the purposes of refining the instrument and establishing probabilistic estimates of item difficulty and learner ability on the same scale. If for example some learners had not taken the test seriously and guessed all the way through, this anomaly would be picked up and for the purposes of developing the scale, these learners would be eliminated. The learners eliminated for the purposes of developing the scale, could still subsequently be allocated a location on the scale for other purposes.

The Rasch model, by locating both items and individual learners on the same scale, provides an answer to the severe criticism of applications of statistics in some psychological research that statistical methods can only provide information on groups of individuals ${ }^{8}$. This class of Rasch models enables "individualcentred statistical techniques" where each individual is characterised separately (Rasch, 1960/1980). It is also possible to develop a profile of individual learners. The clear articulation of qualitative and quantitative information is provided by this model.

\section{Interpretation of the Rasch model}

The results of the assessment were captured and analysed using RUMM software (Andrich, Sheridan, \& Luo, 2007). The resulting person-item distribution map shown in Figure 1 indicates the difficulty of the items on the right, from high difficulty at the top to low difficult at the bottom.

On the left the learners are ranked from high proficiency as measured by this test, at the top, to low proficiency at the bottom. The item mean is set at zero and difficulty levels established through ratio comparisons. The location of learners is calculated in relation to the items and in relation to each other'. For the purposes of this paper, it suffices to say that a learner at a particular point on the scale, for example at $-1.359,50 \%$ of the learners can be expected to have Item 4 correct, less than $50 \%$ of them can be expected to have any specific item higher that Item 4 on the scale correct, and more than $50 \%$ of them can be expected to have any specific item lower that Item 4, for example item 20, correct.

The spread of items and learners along the whole scale indicates that the test functions well. Information on the learners at all levels can be obtained. The lower level of the scale provides information on learners with lower proficiency. Even though five items were added from TIMSS Grade 4, there were some learners for whom even these items had little chance of eliciting a correct response.

\section{Data analysis - percent}

For the purposes of this paper, I have limited the discussion to four items that included the concept of percent and that are located at different levels of difficulty (see Figure 1). From the perspective of teaching and learning, we ask, "What makes these items more or less difficult, and therefore easier or harder to learn?" Vergnaud (1988), drawing from empirical work on elements of the multiplicative conceptual field, reports that the complexity of items depends on the context, the mathematical structure, the presentation (or notation) and the number range used for the problem. The analysis of the items presented here draws on these four constructs.

In addition to locating item difficulty, additional information is provided by distracter analyses. The reasons for learners choosing specific distracters are inferred. These inferences were explored through subsequent interviews at a subsequent phase of the project. The analysis presented here however will remain at the level of a conceptual analysis of items, with empirical support provided by the Rasch model. The four items represented increasing levels of difficulty and by assumption complexity. Table 1 presents the problem description, the context, the mathematical structure and the type of notation used.

\footnotetext{
${ }^{8}$ The details of this story may be read in the forward by Benjamin Wright in Rasch (1960/1980).

${ }^{9}$ The probabilistic process is explained in Andrich and Marais (2008).
} 


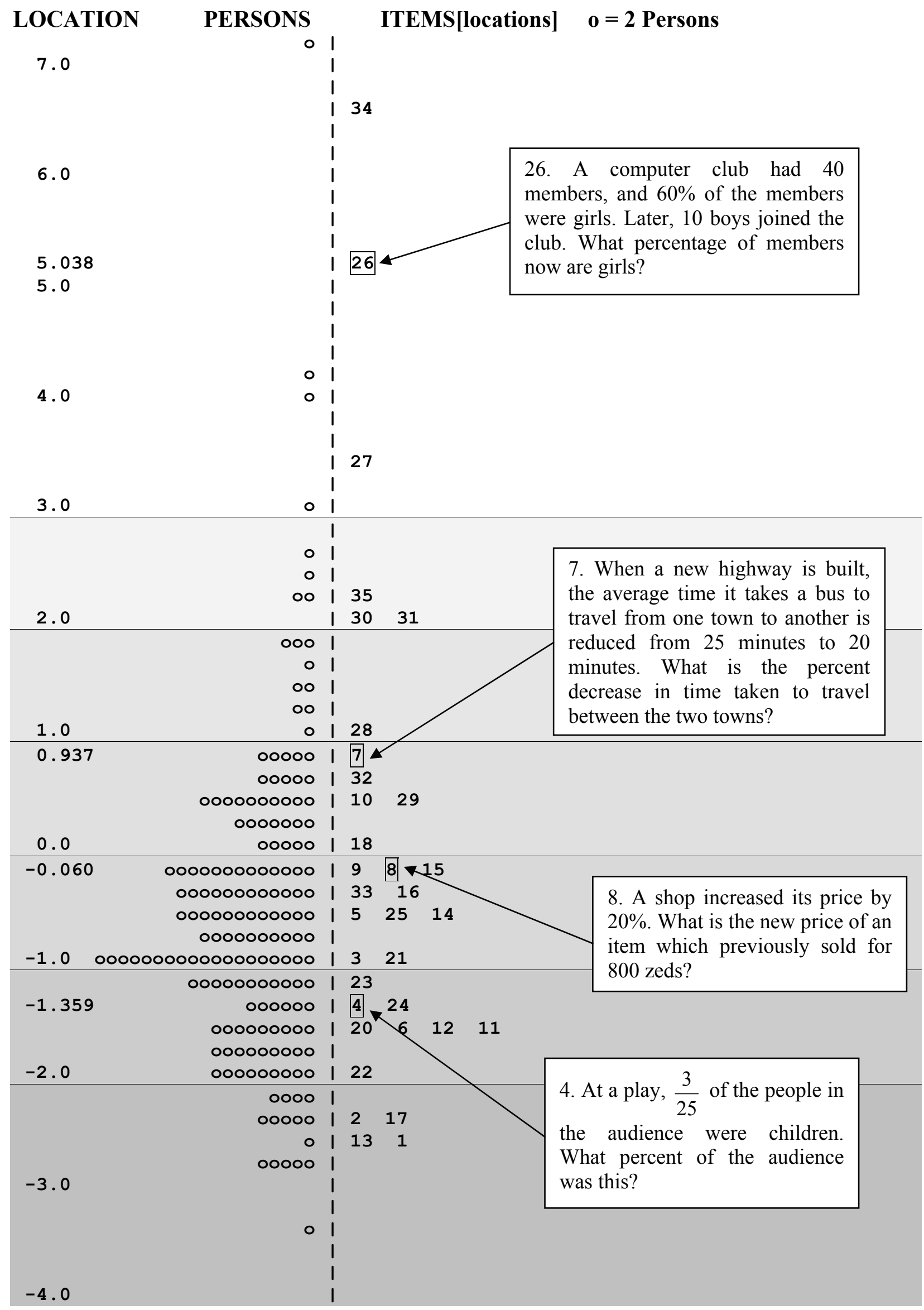

Figure 1: Person-item location distribution 
Table 1: Percent items

\begin{tabular}{|c|c|c|c|}
\hline Description & Context & Mathematical Structure & Notation \\
\hline $\begin{array}{l}\text { 4. At a play, } \frac{3}{25} \text { of the people in the } \\
\text { audience were children. What percent of } \\
\text { the audience was this? }\end{array}$ & $\begin{array}{l}\text { Everyday context } \\
\text { Part-whole }\end{array}$ & $\begin{array}{l}\frac{3}{25} \text { children }(3 \text { out of } 25) \\
\frac{3}{25}=\frac{3 x}{25 x}=\frac{a}{100} \quad \frac{a}{b}=\frac{a x}{b x}\end{array}$ & $\begin{array}{l}\text { Fraction } \\
\text { notation, } \\
\text { percent } \\
\text { notation }\end{array}$ \\
\hline $\begin{array}{l}\text { 8. A shop increased its price by } 20 \% \text {. } \\
\text { What is the new price of an item which } \\
\text { previously sold for } 800 \text { zeds? }\end{array}$ & $\begin{array}{l}\text { Financial context } \\
\text { Price increase }\end{array}$ & $\begin{array}{l}800+20 \% \text { of } 800 \\
100 \% \text { of } 800+20 \% \text { of } 800 \\
=120 \% \text { of } 800\end{array}$ & $\begin{array}{l}\text { Percent } \\
\text { notation }\end{array}$ \\
\hline $\begin{array}{l}\text { 7. When a new highway is built, the } \\
\text { average time it takes a bus to travel from } \\
\text { one town to another is reduced from } 25 \\
\text { minutes to } 20 \text { minutes. What is the } \\
\text { percent decrease in time taken to travel } \\
\text { between the two towns? }\end{array}$ & $\begin{array}{l}\text { Measurement } \\
\text { (time) } \\
\text { Percentage ratio }\end{array}$ & $\begin{array}{l}25-20 \\
\frac{5}{25} \text { converted to percent } \\
\frac{a}{b}=\frac{a x}{b x}\end{array}$ & $\begin{array}{l}\text { Percent } \\
\text { notation }\end{array}$ \\
\hline $\begin{array}{l}\text { 26. A computer club had } 40 \text { members, } \\
\text { and } 60 \% \text { of the members were girls. } \\
\text { Later, } 10 \text { boys joined the club. What } \\
\text { percentage of members now are girls? }\end{array}$ & $\begin{array}{l}\text { Everyday } \\
\text { Part-whole } \\
\text { Percentage ratio }\end{array}$ & $\begin{array}{l}60 \% \text { of } 40=24,40+10=50 \\
\frac{24}{50} \text { convert } \frac{24 \times 2}{50 \times 2} \quad \frac{a}{b}=\frac{a x}{b x}\end{array}$ & $\begin{array}{l}\text { Percent } \\
\text { notation }\end{array}$ \\
\hline
\end{tabular}

Item 4 (location -1.359), a relatively easy item was set in an everyday context that is familiar to most learners. The mathematical structure can be described as a part-whole or fraction-related use of percent. The equivalence concept can be used to convert from a fraction to a decimal or percent. This fraction use of percent is the first use encountered in the curriculum, and it is hypothesised by some research studies (Parker \& Leinhardt, 1995), that learners remain at this fraction meaning of percent notation, and therefore do not progress to a ratio understanding of percent. The use of fraction notation in Item 4 makes the item more difficult than for example items 13, 1, 2, 17 and 22 (see Figure 1) in which natural language is used. The next four items, 20,6,12, and 11 exhibiting fraction notation, were according to the empirical results found to be more difficult than the easiest five items expressed in natural language. While fraction notation is the Item 4 problem, learners are required to operationalise the concept of percent and work with percent notation.

The setting for Item 8 (location -0.060) is a financial situation, which learners may have encountered in a shopping experience ${ }^{10}$. The mathematical structure of the problem requires a ratio understanding of percent, and an understanding of percent notation.

The context for the problem in Item 7 (location 0.937), involves a change in time and a percent decrease. The mathematical construction entails picturing the two time periods (related to the distances travelled), finding the difference, and then finding the ratio of the difference to the original time. This ratio (in fraction form) is then transformed into a percentage. The increase in conceptual difficulty from Item 8 to Item 7 is substantial. This is reflected by the difference between these items on the scale (see Figure 1).

The context for Item 26 (location 5.038) involves a calculation, a change in time and a further calculation. The context can be described as an everyday context, but the problem construction involves two steps with two different uses of percent. The first step is to find $60 \%$ of 40 members (the referent), which is 24 (the number of girls). The referent whole, 40 , then changes (10 boys are added, making 50 ). The next requirement is to convert the 24 (girls) out of 50 (members) into a percentage. This problem involves switching between fraction and percent notations.

\footnotetext{
${ }^{10}$ It is however the mathematical gaze which transforms the shopping experience into a mathematical task, rather than the act of shopping (Dowling, 1998).
} 
Three of the items (Items 4, 8, and 7) were in multiple choice formats for which 4 or 5 response options were provided. Item 26 was presented in a constructed response format. Three of the four items (Items 4, 8 and 26) comprised the equivalence relation, $\frac{a}{b}=\frac{a x}{b x}$. This underlying structure can be regarded as the explicit and generalisable knowledge that can be applied to more than one situation, the power of mathematics that is acquired through the process of transforming intuitive and implicit knowledge that is first encountered in many different situations. Making explicit the mathematical language when describing mathematical concepts and cognitive processes, gives form to the hierarchical progression (1988).

Both Item 8 and Item 26 formed part of the interview phase; detailed information on learner responses has been reported in Long (2008). For the present the discussion will be restricted to the information obtained from the test and from the distracter analyses. Item 8 is given as an example.

\section{Analysis of Item 8}

The RUMM software used to conduct the analysis provides a graph (see Figure 2) showing the choice of options for learners of different proficiency levels. For the purposes of analysis the sample was divided into five quintile groups with approximately 63 learners in each group. The mean of each quintile group is calculated on the performance of learners in that ordinal group on the test as a whole.

On the horizontal axis, the person locations are exhibited. The mean of each group is marked on the horizontal axis by pointers at -2.09 (lowest quintile); $-1.19 ;-0.66 ;-0.02$; and 1.23 (highest quintile).

On the vertical axis the probability of attaining a correct response is exhibited. For example, a learner located at 1.23 (the highest quintile) on the horizontal scale, the frequency of selecting the correct response $\mathrm{C}$ (see line marked 3 ) is $72 \%$. The frequency of selecting D (line marked 4 ), 16\%, of selecting $\mathrm{B}$ (see line 2), $7 \%$, and of selecting A (see line 1), $5 \%$.

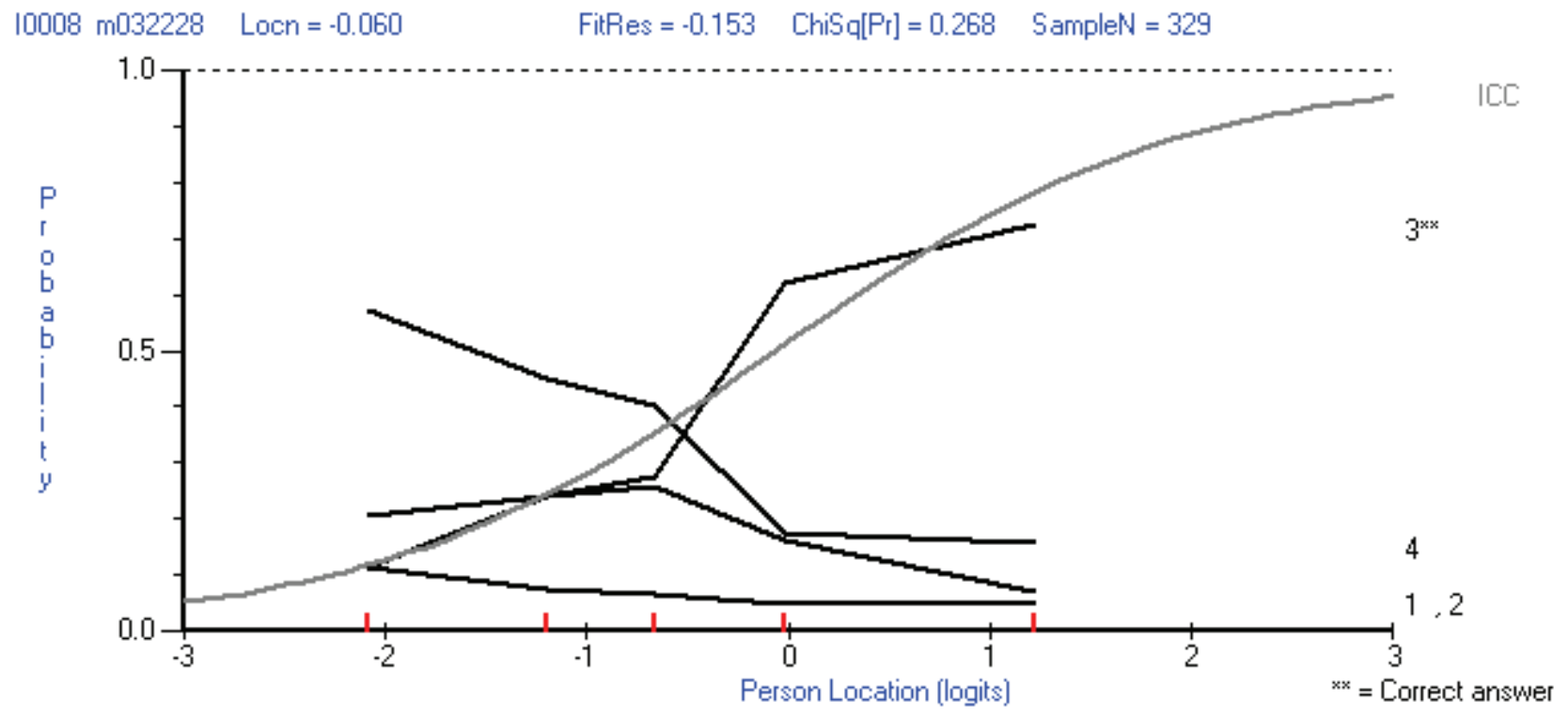

Figure 2: Item 8 distracter analyses for quintile groups

For learners at the low end of the scale, at -2.09 , the frequency of selecting the correct option $\mathrm{C}$ is $11 \%$ (see line 3). The frequency of selecting option D (4) is 57\%. This option was also the most likely choice for the second lowest quintile group. The selection of this distracter was due to a part-whole understanding of percentage, possibly influenced by the presence of 1000 as one of the options. The learners at the lower end of the scale, it is inferred, have remained at the early cognitive stage of learning percentage, where fractions, decimals and percent notation are used interchangeably. 
This disaggregated information shown in Figure 2, provides the researcher, and teacher, with relevant information. The single statistic, that $60 \%$ of the class got this item correct, is replaced with more useful information about different subgroups, which range from $72 \%$ (the highest quintile), to $11 \%$ (the lowest quintile), respectively of learners selecting the correct response.

The additional information about what kinds of conceptual errors are made is also useful. The information on the distracters as well as inferred reasons is shown in Table 2, in which the information is provided in numerical form.

Table 2: Inferred mathematical procedure for responses by quintile group

\begin{tabular}{lllllll}
\hline & & \multicolumn{3}{c}{ Mean locations of 5 quintile groups } \\
\cline { 3 - 6 } Choice & Inferred mathematical procedure & -2.09 & -1.19 & -0.66 & -0.02 & 1.23 \\
C. 960 zeds & Percentage increase & $11 \%$ & $24 \%$ & $20 \%$ & $62 \%$ & $72 \%$ \\
D. 1000 zeds & $\begin{array}{l}\text { Part whole } 800 \text { to } 1000 \text { increase represents 20\% of } \\
\text { final amount }\end{array}$ & $57 \%$ & $45 \%$ & $40 \%$ & $17 \%$ & $16 \%$ \\
B. 900 zeds & Estimate a number greater than 800 & $21 \%$ & $24 \%$ & $26 \%$ & $16 \%$ & $7 \%$ \\
A. 640 zeds & Decrease by 20\% rather than increase - misreading & $11 \%$ & $7 \%$ & $6 \%$ & $5 \%$ & $5 \%$ \\
\hline
\end{tabular}

After option $\mathrm{C}$ and $\mathrm{D}$, distracter B elicited the most responses. This preponderance may have been due to the fact that learners estimated an answer greater than 800. Distracter A may have been selected on account of carelessness.

\section{Conclusion}

The transitions from whole number to real number, requires an understanding of concepts such as fraction and ratio, elements of the multiplicative conceptual field. An operational understanding attained through working with these concepts provides the basis for an understanding of rational number. The shift from the "conceptualization of the ratios of integers from relations between numbers to numbers [themselves]" is necessary for understanding the threshold concept rational number (Vamvakoussi \& Vosniadou, 2007, p. 266, my emphasis). This understanding of rational numbers is a necessary pre-curser to understanding irrational numbers, and therefore real numbers, which provides the conceptual gateway to higher order concepts.

Parker and Leinhardt (1995) remind us that percent is a complex construct where the underlying referent is not always made explicit. Percent builds on fractions and ratio; in some ways functioning like fractions and decimals, but in many ways differently, for example, one cannot add percentages unless the referent populations are equivalent or equal.

It is tempting to think that access to the historical account of discovering irrational numbers and the Eudoxian resolution of the crisis confronting mathematicians would enable understanding of incommensurability ${ }^{11}$. The answer emerging from this research study is that this historical insight may contribute to conceptual understanding, but the true concept cannot be attained without some cognitive engagement on the part of the learner assisted by carefully constructed situations that provide a context, with which learners feel familiar but which demand the development of further mathematical understanding and the associated development of cognitive processes.

\footnotetext{
11 The introduction via decimal numbers, invented centuries later than the discovery of irrational numbers, circumvents the very crisis and potential understanding of irrational numbers and incommensurability, these concepts being the precursors to the understanding of non-terminating and non-repeating decimal numbers.
} 
In an appeal for greater regard for the complexity underlying the language of percent, Parker and Leinhardt (1995) propose that attention be given to the underlying mathematical structure of percent and the complex relationship between percent and the related concepts of ratio, proportion, fractions and functions. Vergnaud (1988) proposes that research into the learning and teaching of mathematics requires both a mathematical view and a psychological view, and that conceptual analysis of the mathematical situations, and observation of cognitive schemes that are engaged in the solving of these situations, be described using mathematical terminology. This approach enables the teacher and researcher to locate the learner on a mathematical path.

It has been acknowledged that educational measurement as it manifests in testing and statistics may be a rather blunt instrument for the fine qualitative distinctions required to understand teaching and learning. The Rasch measurement model however, is sensitive to qualitative nuances and indeed requires subject experts to engage at all levels of the assessment process, from the conceptualisation of the construct to the analysis and interpretation of the data. In this study the Rasch model and the aligned software have enabled finer degrees of understanding of this complex field.

\section{References}

Andrich, D., \& Marais, I. (2008). Introductory course notes: Instrument design with Rasch, IRT and data analysis. Perth: University of Western Australia.

Andrich, D., Sheridan, B. E., \& Luo, G (2007). RUMM2020 (Rasch Unidimensional Measurement Model, version 4.3) [Computer software]. Perth, Western Australia: RUMM Laboratory.

Cai, J., \& Sun, W. (2002). Developing students' proportional reasoning. In B. Litwiller \& G. Bright (Eds.), Making sense of fractions, ratios and proportions (pp. 195-212). Reston, VA: National Council of Teachers of Mathematics.

Department of Education. (2002). Revised national curriculum statement Grade R-9 (Schools). Mathematics. Pretoria: Department of Education,

Dowling, P. (1998). The sociology of mathematics education: Mathematical myths/pedagogical texts. London: Falmer Press.

Eves, H. (1980). Great moments in mathematics (before 1650). Washington, DC: The Mathematical Association of America.

Eves, H. (1990). An introduction to the history of mathematics. Pacific Grove, CA: Brooks/Cole-Thomson Learning.

Hart, K. (1981). Children's understanding of mathematics: 11-16. Oxford: John Murray.

Long, C. (2006a, January). The conceptual and historical development of ratio. Paper presented at the conference of the Southern African Association for Research in Mathematics, Science and Technology Education. University of Pretoria, Pretoria.

Long, C. (2006b, July). Beyond the bad news: Diagnostic implications of TIMSS 2003. Paper presented at conference of the Association for Evaluation and Assessment in Southern Africa. University of Johannesburg, Johannesburg.

Long, C. (2008, January). Ratio, proportion and percent: Using the Rasch model to establish focus points. Paper presented at the Third International Rasch Conference. University of Western Australia, Perth.

Meyer, J. H. F., \& Land, R. (2005). Threshold concepts and troublesome knowledge (2): Epistemological considerations and a conceptual framework for teaching and learning. Higher Education, 49, 373-388.

Mullis, I. V. S., Martin, M. O., Smith, T. A., Garden, R. A., Gregory, K. D., \& Gonzalez, E. J.(2003). TIMSS assessment frameworks and specifications 2003. Chestnut Hill, MA: International Study Centre, Boston College.

Parker, M., \& Leinhardt, G. (1995). Percent: A privileged proportion. Review of Educational Research, 65(4), 421-481.

Rasch, G. (1960/1980). Probabilistic models for some intelligence and attainment tests. (Copenhagen: Danish Institute for Educational Research), expanded edition (1980) with foreword and afterword by B. D. Wright. Chicago: The University of Chicago Press.

Reddy, V. (2006). Mathematics and science achievement at South African schools in TIMSS 2003. Cape Town: Human Sciences Research Council.

Skemp, R. (1971). The psychology of learning mathematics. Harmondsworth: Penguin. 
Smith III, J. P. (2002). The development of students' knowledge of fractions and ratios. In B. Litwiller \& G. Bright (Eds.), Making sense of fractions, ratio and proportions (pp. 3-17). Reston, VA: The National Council of Teachers of Mathematics.

Taylor, N. (2007). Equity, efficiency and the development of South African schools. In T. Townsend (Ed.), International handbook of school effectiveness and improvement (pp. 523-540). New York: Springer.

Usiskin, Z. (2005). The importance of the transition years, Grades 7-10, in school mathematics. UCSMP Newsletter. Spring 2005.

Vamvakoussi, X., \& Vosniadou, S. (2007). How many numbers are there in a rational number interval? Constraints, synthetic models and the effect of the number line. In S. Vosniadou, A. Baltas, \& X. Vamvakoussi (Eds.), Reframing the conceptual change approach in learning and instruction (pp. 265282). Oxford: Elsevier.

Vergnaud, G. (1988). Multiplicative structures. In J. Hiebert \& M. Behr (Eds.), Number concepts and operations in the middle grades (pp.141-161). Hillsdale, NJ: Lawrence Erlbaun Associates.

Vergnaud, G. (1998). A comprehensive theory of representation for mathematics education. Journal of Mathematical Behaviour, 17(2), 167-181.

Wright, B. D., \& Stone, M. H. (1979). Best test design. Chicago: MESA Press. 